\title{
Data-Syntactic Regression of Ill-Being
}

\author{
Gordon G. Bechtel ${ }^{1 *}$ \\ ${ }^{1}$ University of Florida and Florida Research Institute
}

\begin{abstract}
Panel data transcends cross-sectional data by tapping pooled inter- and intra-individual differences, along with between and within individual variation separately. In the present study these micro variations in ill-being are predicted by psychological indicators constructed from the British Household Panel Survey (BHPS). Panel regression effects are corrected for errors-in-variables, which attenuate slopes estimated by traditional panel regressions. These corrections reveal that unhappiness and life dissatisfaction are distinct variables that have different psychological causations.
\end{abstract}

Key words: Depression, Life dissatisfaction, Measurement error, Panel data syntaxes, True-value regression, Unhappiness.

\section{Social Indicators and Mental Health}

\subsection{Dissatisfaction and unhappiness as separate dimensions of ill-being}

Conflating constructs. Tatarkiewicz (1976, pp. 35-36) emphasized that

The history of the concept of happiness, stretching over two thousand years, is not a simple one. In early times 'happiness' meant simply success. Then for centuries, covering much of antiquity and the middle ages, it signified a man's perfect condition or the possession by him of the highest virtues and goods. Modern times reduced happiness to pleasure. Today, without discarding these earlier notions, we employ yet another concept of happiness. ...

For each man is either satisfied or dissatisfied with his life and gives expression to this feeling. But to be satisfied with life is not the same thing as to attain perfection or to enjoy a long succession of pleasures.

This modern conflation of happiness and satisfaction was picked up in the 1970's by the social indicators movement in three different ways. First, Andrews and Withey (1974) introduced the following life quality scale in the lead article of the maiden issue of Social Indicators Research:

Terrible Unhappy $\begin{gathered}\text { Mostly Equally satisfied } \\ \text { dissatisfied and dissatisfied }\end{gathered}$ Satisfied
andeased Delighted

This sequence of response labels presumes that (dis)satisfaction constitutes the core of a wellbeing continuum, and that (un)happiness constitutes the extremes of this single dimension.

\footnotetext{
* Corresponding author.
} 
Second, Atkinson (1982) constructed a life-quality index by combining responses to life satisfaction and happiness questions. Similarly, Inglehart and Klingemann (2000) took an average of survey responses for happiness and satisfaction as their measure of life quality. This conflation was severely criticized by Guttman and Levy (1982, p. 160) as succumbing "to the widespread looseness of terminology in confusing 'varieties' of behavior with 'components' of behavior".

The third conflation of satisfaction and happiness is seen in the work of Veenhoven (1991) and Van Praag and Ferrer-i-Carbonell (2004). These authors simply regard satisfaction and happiness as synonymous and use satisfaction responses to quantify happiness.

Distinguishing constructs. Breaks in this conflation by the social indicators movement appeared in 2004. Gundelach and Kreiner (2004, p.363) concluded that happiness and satisfaction are correlated, distinct variables. In this same year Michalos, who has edited Social Indicators Research since its inception in 1974, noted that

... different people have had very different ideas about the nature of happiness or of an overall good quality of life ... virtually all research has shown that happiness and life satisfaction share some common meaning ... when people talk about satisfaction or happiness with their whole lives, they are typically referring to a relatively lasting, justified, good feeling and attitude about their lives. ... However, because measures of happiness and life satisfaction do not have identical connotations or denotations, it is worthwhile to analyze their components and correlates separately. (Michalos 2004, p. 37-38)

A more recent distinction between happiness and satisfaction comes from the Well-Being Institute \& Department of Psychiatry, University of Cambridge. Huppert and So (2013, p. 839), also writing in Social Indicators Research, emphasize that

... well-being is multi-dimensional. This contrasts sharply with the long-standing assumption, made in generations of economic and social surveys, that positive human experience can be adequately assessed using a single item about life satisfaction or happiness.

The present paper strengthens this multi-dimensionality with the discovery that different aspects of depression drive unhappiness and dissatisfaction in very different ways.

\subsection{The role of depression in ill-being}

T.G. Bechtel (2007) found that mental distress was the strongest driver of life dissatisfaction as self-reported on the British Household Panel Survey (BHPS) and the European Social Survey (ESS). He noted (p.111) that earlier results in the social indicators literature had implicated mental distress in the quality of life:

... Michalos (2004), in reporting the results of eleven different surveys from 1979 until 2000, found that self-esteem was the leading predictor of happiness. He also reports the results of another 1998 survey showing that happiness scores strongly regressed on measures of mental health, depression, and selfesteem $\left(R^{2}=0.53\right)$. The earlier work of Andrews and Whitey (1976) found self-efficacy to be the most important predictor of overall well-being. Thus, the research on quality of life, beginning with Bradburn (1969), demonstrates the importance of psychological determinants of happiness.

Keyes (2007, p. 98) also pointed out

It is noteworthy that subjective well-being research unintentionally yielded clusters of mental health symptoms that mirror the clusters of symptoms used in the Diagnostic and Statistical Manual of Mental 
Disorders.....In the same way that depression requires symptoms of an-hedonia, mental health consists of symptoms of hedonia such as emotional vitality and positive feelings towards one's life. In the same way that major depression consists of symptoms of mal-functioning, mental health consists of symptoms of positive functioning.

A rather extreme application of Keyes observation has been proposed by Huppert and So (2013, p. 837):

A conceptual framework is offered which equates high well-being with positive mental health. Wellbeing is seen as lying at the opposite end of a spectrum to the common mental disorders (depression, anxiety).

Factor analyzing items from the third round of the ESS, these authors find two factors, "feeling good" and "functioning well" (cf. Keyes, 2007), which they propose as separate dimensions of well-being or flourishing.

Rather than accepting this new conflation of ill-being and depression, the present paper retains unhappiness and dissatisfaction as the classic dimensions of ill-being. We then find these dimensions to be driven in very different ways by affective and cognitive depression, i.e. "feeling bad" and "functioning badly" (cf. Huppert and So, 2013). Thus, unlike these later authors, we regard depression as a cause rather than the essence of ill-being.

\subsection{The study plan}

Section 2 describes the two depression factors we extract from The United Kingdom's General Health Questionnaire, which is included in the British Household Panel Survey. Section 3 deconstructs our BHPS depression and ill-being scores into true scores and measurement errors. Section 4 describes an unbalanced census panel and the weighted sampling of panelists from this census. Sections 5 and 6 generalize randomization-based panel regressions (Bechtel, 2014) to true-value panel regressions of overall-, between-, and within-panelist data. Section 7 shows that all three data syntaxes sustain a dramatic role reversal for affective and cognitive depression in predicting ill-being. Section 8 points up the usefulness of true-value regression in a) removing measurement error from survey scores and b) sharpening the distinction between unhappiness and life dissatisfaction in social-indicators research. This final section also advocates true-value regression in the data syntaxes of cross-national surveys carried out at a single time point.

\section{Dimensions of Depression: The General Health Questionnaire}

Links between social indicators and health have been investigated by the United Kingdom's Health Development Agency. In one of the studies funded by this agency, Pevalin (2000, p.508) notes

The General Health Questionnaire (GHQ) has been used as a screening instrument for minor psychiatric disturbance in numerous clinical studies as well as an indicator of psychiatric morbidity in large-scale community-based surveys.

... The aim of this study was to examine data from a large general population sample for evidence of any retest effects over 7 yearly applications. Methods: A core panel was drawn from the British Household 
Panel Survey of those respondents who had completed the GHQ-12 seven times from 1991 to 1997 ( $n=$ 4749). The panel results were compared with cross-sectional data from the Health Surveys for England for the same years. ... Results: No evidence of retest effects was found. ... Conclusion: The GHQ-12 is a consistent and reliable instrument when used in general population samples with relatively long intervals between applications.

In his review of the GHQ for Occupational Medicine, Jackson (2007, p.79) indicates that this instrument

$\cdots$ has been translated into 38 different languages, testament to the validity and reliability of the questionnaire. ... Possibly, the most common assessment of mental well-being is the GHQ. Developed as a screening tool to detect those likely to have or be at risk of developing psychiatric disorders, it is a measure of the common mental health problems ...

Table 2 exhibits the twelve items making up a short version of the General Health Questionnaire known as the GHQ-12. (The second dissatisfaction item in Table 2 is not part of this questionnaire.) The GHQ-12 is a dedicated, widely-used psychiatric instrument whose interitem correlations range between .21 and .69. This correlation range is considerably higher than that (.10 to .49) for the ad hoc depressive antonyms used by Huppert and So (2013).

T. G. Bechtel (2007) found the GHQ-12 to be the strongest predictor of self-reported life satisfaction on the BHPS. The present study pursues this finding by factoring GHQ-12 items into two dimensions and using the resulting depression scales as predictors of unhappiness and life dissatisfaction separately. Our analysis is restricted to the eleven symptomatic items in the GHQ-12 because the item on overall unhappiness is our dependent variable. These eleven symptoms were submitted to the oblique factor analysis exhibited in Table 1. The items marking the two oblique dimensions are described in Tables 1 and 2 under the labels of affective and cognitive depression. These terms, which connote distressing experience and the inability to carry out normal functions, are antonyms of Huppert's and So's (2013) "feeling good" and "functioning well". However, due to the higher correlations among GHQ-12 items than among Huppert's and So's ESS items, the factor loadings in Table 1 exhibit a sharper distinction between these two dimensions. 
Table 1: Oblique Factor Analysis of the General Health Questionnaire

\begin{tabular}{lcc}
\hline GHQ item & $\begin{array}{l}\text { Affective } \\
\text { depression }\end{array}$ & $\begin{array}{c}\text { Cognitive } \\
\text { depression }\end{array}$ \\
\hline Constantly under strain & $\mathbf{. 9 7}$ & -.27 \\
Losing sleep over worry & $\mathbf{. 8 9}$ & -.21 \\
Unhappy or depressed & $\mathbf{. 8 9}$ & -.07 \\
Can't overcome difficulties & $\mathbf{. 8 3}$ & -.04 \\
Losing confidence in myself &. $\mathbf{7 1}$ & .11 \\
Feeling like a worthless person & $\mathbf{. 6 2}$ & .14 \\
Incapable of making decisions & -.20 & $\mathbf{. 9 4}$ \\
Not playing a useful part in things & -.17 & $\mathbf{. 8 8}$ \\
Can't face up to problems & .05 &. $\mathbf{7 4}$ \\
Can't concentrate on whatever I'm doing & .19 & $\mathbf{. 5 7}$ \\
Can't enjoy my normal daily activities & .23 & $\mathbf{. 5 4}$ \\
\hline
\end{tabular}

Note. These rotated factor loadings were obtained from an oblimax rotation of principal components.

\section{Observed Scores, True Scores, and Measurement Error}

By including the GHQ-12 and various satisfaction items, the BHPS

(http://www.esds.ac.uk/longitudinal) allows us to assess the effects of affective and cognitive depression on unhappiness and life dissatisfaction. Table 2 exhibits the 13 BHPS items that measure these four constructs.

\subsection{Equally-spaced response codes}

Unhappiness. The first item in Table 2 is actually the last item on the GHQ-12. We code its responses in three equal steps between zero and ten. Let $U_{\text {it }}$ be our coding of the response label chosen by individual i on wave t. We deconstruct this coding as

$$
\mathrm{U}_{\mathrm{it}}=\eta_{\mathrm{it}}+\mathrm{K}_{\mathrm{it}} \text {, }
$$

where $\eta_{\mathrm{it}}$ is true unhappiness and $\mathrm{K}_{\mathrm{it}}$ is a coding error in measuring this characteristic. The values $\eta$ it and $\mathrm{K}_{\mathrm{it}}$ lie on a continuous interval scale whose origin and unit are set by coding the extreme response labels, more so than usual and much less than usual, as zero and ten. 
Measurement error is the departure of respondent i's selected coding, 0, 3.33, 6.67, or 10, from her (his) true value $\eta_{\text {it }}$.

Life dissatisfaction. The second item in Table 2 is coded in six equal steps. Again the origin and unit of this scale are set by coding completely satisfied as zero and not satisfied at all as ten. Let $\mathrm{D}_{\mathrm{it}}$ denote our coding of the response label that i selects on wave $t$. Then

$$
\mathrm{D}_{\mathrm{it}}=\tau_{\mathrm{it}}+\mathrm{F}_{\mathrm{it}},
$$

where $\tau_{\mathrm{it}}$ is i's true dissatisfaction on the continuous scale $[0,10]$. Measurement error $\mathrm{F}_{\mathrm{it}}$ is the departure of the selected coding, $0,1.67,3.33,5,6.67,8.33$, or 10 , from $\tau_{\mathrm{it}}$.

The common interval scale. The interval scale shared by all items in Table 2 allows a comparison of the unhappiness and dissatisfaction regression slopes computed in the present paper. This scale tolerates

- the different numbers of response options for the first two items in Table 2, and

- the equal spacing of response codes, which depart from true values.

These departures $K_{i t}$ and Fit are assumed to satisfy the classical error properties given in the last paragraph of Section 5.1.

\subsection{Multiple-item scores}

Affective depression. An individual's affective depression score, which also contains measurement error, is an average of six item responses. Still referring to Table 2, we deconstruct i's affective-depression item coding on wave $t$ as

$$
A_{i t m}=\rho_{i t}+G_{i t m} \quad \text { for } m=1 \ldots 6 .
$$

On wave $t$ each item $m$ measures i's true affective depression $\rho_{\text {it }}$ with error $G_{i t m}$ on our common scale $[0,10]$, i.e. $\mathrm{G}_{\mathrm{itm}}$ is the departure of coding $\mathrm{A}_{\mathrm{itm}}\left(=0,3.33,6.67\right.$, or 10) from $\rho_{\mathrm{it}}$.

Individual i's affective-depression score on wave $t$ is the average of her (his) six response codings:

$$
\begin{aligned}
A_{i t} & =\left(A_{i t 1}+A_{i t 2}+A_{i t 3}+A_{i t 4}+A_{i t 5}+A_{i t 6}\right) / 6 \\
& =\rho_{i t}+\left(G_{i t 1}+G_{i t 2}+G_{i t 3}+G_{i t 4}+G_{i t 5}+G_{i t 6}\right) / 6 \\
& =\rho_{i t}+G_{i t} .
\end{aligned}
$$

$G_{i t}$ in (3.3) is i's error score on wave t, which is the deviation of her (his) score $A_{i t}$ from $\rho_{i t}$.

Cognitive depression. Finally, we derive cognitive depression scores as averages of five item response codes. A cognitive-depression item coding in Table 2 is decomposed as

$$
\mathrm{C}_{\mathrm{itm}}=v_{\mathrm{it}}+\mathrm{H}_{\mathrm{itm}} \quad \text { for } \mathrm{m}=1 \ldots 5,
$$

where item m measures i's true cognitive depression vit on wave $t$ with error $\mathrm{H}_{\mathrm{itm}}$. Her (his) cognitive depression score on wave $t$ is 


$$
\begin{aligned}
\mathrm{C}_{\mathrm{it}} & =\left(\mathrm{C}_{\mathrm{it} 1}+\mathrm{C}_{\mathrm{it} 2}+\mathrm{C}_{\mathrm{it} 3}+\mathrm{C}_{\mathrm{it} 4}+\mathrm{C}_{\mathrm{it} 5}\right) / 5 \\
& =v_{\mathrm{it}}+\left(\mathrm{H}_{\mathrm{it} 1}+\mathrm{H}_{\mathrm{it} 2}+\mathrm{H}_{\mathrm{it} 3}+\mathrm{H}_{\mathrm{it} 4}+\mathrm{H}_{\mathrm{it} 5}\right) / 5 \\
& =v_{\mathrm{it}}+\mathrm{H}_{\mathrm{it}} .
\end{aligned}
$$

The error score $\mathrm{H}_{\mathrm{it}}$ in (3.4) is the deviation of observed score $\mathrm{C}_{\mathrm{it}}$ from $v_{\mathrm{it}}$ on our common interval scale $[0,10]$.

Table 2: Construct and Item Scores

BHPS items and scales

Common interval-scale coding

Unhappiness

$\begin{array}{lllll}\text { Uit } & 0 & 3.33 & 6.67 & 10\end{array}$

Have you recently been feeling reasonably happy, all things considered ?

More so than usual Same as usual Less so than usual Much less than usual

\section{Dissatisfaction}

Dit 01.673 .3356 .678 .3310

How dissatisfied or satisfied are you with your life overall ?

\begin{tabular}{ccccccc}
$\begin{array}{c}\text { Completely } \\
\text { satisfied }\end{array}$ & \multicolumn{3}{c}{$\begin{array}{c}\text { Not satisfied } \\
\text { or dissatisfied }\end{array}$} & & Not satisfied \\
1 & 2 & 3 & 4 & 5 & 6 & 7
\end{tabular}

\section{Affective-depression}

Ait $0 \ldots \ldots \ldots . . . . . . . . . .10$

Have you recently ....

lost much sleep over worry?

Not at all No more than usual Rather more than usual

Much more than usual

$\begin{array}{lllll}\mathrm{A}_{\text {it1 }} & 0 & 3.33 & 6.67 & 10\end{array}$

felt constantly under strain ?

Not at all No more than usual Rathermore Much more

$\begin{array}{lllll}\mathrm{A}_{\text {it2 }} & 0 & \mathbf{3 . 3 3} & \mathbf{6 . 6 7} & 10\end{array}$

felt you couldn't overcome your difficulties ?

Not at all Nomore than usual Rathermore Much more

$\begin{array}{lllll}\mathrm{A}_{\mathrm{it} 3} & 0 & \mathbf{3 . 3 3} & \mathbf{6 . 6 7} & 10\end{array}$

been feeling unhappy or depressed ?

Not at all No more than usual Rather more Much more

$\mathrm{A}_{\text {it4 }} \quad \begin{array}{llll}\mathbf{3} & \mathbf{3 3} & \mathbf{6 . 6 7} & 10\end{array}$

been losing confidence in yourself ?

Not at all Nomore than usual Rathermore Much more

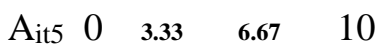

been thinking of yourself as a worthless person?

Not at all No more than usual Rathermore Much more 


\section{Cognitive depression}

Cit $0 \ldots \ldots \ldots \ldots \ldots \ldots . . . .10$

Have you recently ....

been able to concentrate on whatever you're doing?

Better than usual Same as usual Less than usual

Much less than usual

$\begin{array}{lllll}\mathrm{C}_{\mathrm{it} 1} & 0 & \mathbf{3 . 3 3} & \mathbf{6 . 6 7} & 10\end{array}$

felt that you were playing a useful part in things ?

More than usual Same as usual Less so Much less

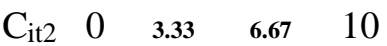

felt capable of making decisions about things ?

More so than usual Same as usual Less so than usual Much less capable

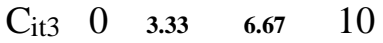

been able to enjoy your normal day-to-day activities ?

$\begin{array}{lllllll}\text { More so than usual } \quad \text { Same as usual } & \text { Less so than usual } & \text { Much less than usual } \\ \mathrm{C}_{\mathrm{it} 4} & 0 & \mathbf{3 . 3 3} & \mathbf{6 . 6 7} & 10\end{array}$

been able to face up to problems?

More so than usual $\quad$ Same as usual Less so than usual Much less than usual

$\begin{array}{lllll}\mathrm{C}_{\mathrm{it} 5} & 0 & \mathbf{3 . 3 3} & \mathbf{6 . 6 7} & 10\end{array}$

Source: The item wording and response labels in this table are taken from the British Household Panel Survey (https://www.iser.essex.ac.uk/bhps/). The common interval-scale coding on the right side of the table is used by the author to render regression slopes comparable (cf. equations 3.1-3.4).

\section{Census and Sample Panels}

Define a vector $Y_{i t} \equiv\left(U_{i t} D_{i t} A_{i t} C_{i t}\right)^{T}$ whose elements are the scores in (3.1) - (3.4). The term panelist denotes an intra-individual sequence of vectors $Y_{\text {it }}$ illustrated by a single row in Table 3 . The rows of Table 3 make up an unbalanced census panel in which panelists have different numbers of wave appearances due to attrition and/or late panel entry. More generally, in an unbalanced census panel each panelist $i$ appears in $t=1 \ldots T_{i}$ waves for $i=1 \ldots N$. Subscript $t=$ 1 denotes individual i's first appearance even though her (his) panel entry may occur later than wave 1.

The italic boldface rows in Table 3 illustrate an unbalanced sample panel of $n=3$ panelists drawn from an unbalanced census panel of $\mathrm{N}=7$ panelists. Each longitudinal weight in the last column of Table 3 is calculated from the probability of that sampled individual being monitored over her (his) particular sequence of waves within a time span of four waves. For example, the weight $\mathrm{w}_{2}$ reflects the probability of panelist 2 being drawn in the sample at wave 1 and giving a full interview on waves $1,2,3$ and 4 . The construction of longitudinal weights for sampled panelists is given in detail by the BHPS (http://www.esds.ac.uk/longitudinal). These longitudinal weights are used in all six true-value regressions reported in Section 7.3.

Table 3 illustrates the data used in three kinds of panel regressions developed in Sections 5 and 6. Each data-syntactic regression is posed for our hypothetical census panel and run for our 
realized sample panel. Thus, in Table 3 an un-weighted census regression is posed over 22 individual-wave observations. This census regression generates target parameters, which are estimated by a weighted sample regression run over 9 individual-wave observations.

Table 3: Unbalanced census and sample panels

\begin{tabular}{|c|c|c|c|c|c|c|}
\hline Panelist & Measure 1 & Measure 2 & Measure 3 & Measure 4 & $\begin{array}{l}\text { Panelist } \\
\text { mean }\end{array}$ & $\begin{array}{c}\text { Panelist } \\
\text { weight }\end{array}$ \\
\hline Individual 1 & $\mathrm{Y}_{11}$ & $\mathrm{Y}_{12}$ & $\mathrm{Y}_{13}$ & $\mathrm{Y}_{14}$ & $\mathrm{Y}_{1}$ & \\
\hline Individual 2 & $Y_{21}$ & $Y_{22}$ & $Y_{23}$ & $Y_{24}$ & $Y_{2}$ & $w_{2}$ \\
\hline Individual 3 & $\mathrm{Y}_{31}$ & $\mathrm{Y}_{32}$ & $\mathrm{Y}_{33}$ & $\mathrm{Y}_{34}$ & $\mathrm{Y}_{3}$ & \\
\hline Individual 4 & $Y_{41}$ & $Y_{42}$ & $Y_{43}$ & & $Y_{4}$ & $w_{4}$ \\
\hline Individual 5 & $\mathrm{Y}_{51}$ & $\mathrm{Y}_{52}$ & $\mathrm{Y}_{53}$ & & $\mathrm{Y}_{5}$ & \\
\hline Individual 6 & $Y_{61}$ & $Y_{62}$ & & & $Y_{6}$. & $w_{6}$ \\
\hline Individual 7 & $\mathrm{Y}_{71}$ & $\mathrm{Y}_{72}$ & & & $\mathrm{Y}_{7}$ & \\
\hline
\end{tabular}

Note: This table is taken from Bechtel (2014). The column labels denote wave appearances. Thus individual 1 entered the census panel on its first wave. However, individual 7 may have actually entered this panel on its first, second, or third waves.

\section{True-Value Regression in Data Syntax it}

\subsection{True parameter identification}

Following our illustration in Section 4, we posit sets of census scores, true scores, and error scores:

$$
\begin{aligned}
& \left\{U_{\text {it }} D_{\text {it }} A_{i t} C_{i t}\right\}, \\
& \left\{\eta_{i t} \tau_{\text {it }} \rho_{i t} V_{i t}\right\}, \text { and } \\
& \left\{K_{i t} F_{i t} G_{i t} H_{i t}\right\},
\end{aligned}
$$

where $t=1 \ldots T_{i}$ for $i=1 \ldots N$. The first set is hypothetically computed from a posited census of the 13 items described in Section 3. The second set of true scores is in one-to-one correspondence with the set of census scores. The third set is the difference set of error scores. 
True unhappiness and dissatisfaction regressions may then be written as

$$
\begin{aligned}
& \eta_{i t}=\kappa+\beta \rho_{i t}+\theta v_{i t}+\varepsilon_{i t} \text { and } \\
& \tau_{i t}=\lambda+\gamma \rho_{i t}+\omega v_{i t}+v_{i t},
\end{aligned}
$$

where $t=1 \ldots T_{i}$ for $i=1 \ldots \mathrm{N}$ and cit and vit are specification errors. The intercepts and slopes in (5.1a) and (5.1b) are identified by

$$
\begin{aligned}
& (\kappa \beta \theta)^{\mathrm{T}}=\left[\Sigma \mathrm{X}_{\mathrm{it}} \mathrm{X}_{\mathrm{it}}^{\mathrm{T}}\right]^{-1} \Sigma \mathrm{X}_{\mathrm{it}} \eta_{\mathrm{it}}=\left[\Sigma \mathrm{Z}_{\mathrm{it}} \mathrm{Zit}^{\mathrm{T}}-\Delta\right]^{-1} \Sigma \mathrm{Z}_{\mathrm{it}} \mathrm{U}_{\mathrm{it}} \text { and } \\
& (\lambda \gamma \omega)^{\mathrm{T}}=\left[\Sigma \mathrm{X}_{\mathrm{it}} \mathrm{X}_{\mathrm{it}}^{\mathrm{T}}\right]^{-1} \Sigma \mathrm{X}_{\mathrm{it}} \tau_{\mathrm{it}}=\left[\Sigma \mathrm{Z}_{\mathrm{it}} \mathrm{Z}_{\mathrm{it}}^{\mathrm{T}}-\Delta\right]^{-1} \Sigma \mathrm{Z}_{\mathrm{it}} \mathrm{D}_{\mathrm{it}},
\end{aligned}
$$

where the totals run over $\mathrm{t}=1, \ldots, \mathrm{T}_{\mathrm{i}}$ for $\mathrm{i}=1, \ldots, \mathrm{N}$. In these equations $\mathrm{X}_{\mathrm{it}}=\left(1 \rho_{\mathrm{it}} \mathrm{v}_{\mathrm{it}}\right)^{\mathrm{T}}, \mathrm{Z}_{\mathrm{it}}$ $=\left(1 \mathrm{~A}_{\mathrm{it}} \mathrm{C}_{\mathrm{it}}\right)^{\mathrm{T}}$, and $\Delta=\operatorname{diag}\left(0 \delta_{\rho} \delta_{v}\right)$, where error sums of squares

$$
\begin{aligned}
& \delta_{\rho}=\sum_{\mathrm{it}} \mathrm{G}_{\mathrm{it}}^{2}=\left(1-\alpha_{\rho}\right)\left\{\sum_{\mathrm{it}} \mathrm{A}_{\mathrm{it}}^{2}-\left(\sum_{\mathrm{it}} \mathrm{A}_{\mathrm{it}}\right)^{2} / \Sigma_{\mathrm{i}} \mathrm{T}_{\mathrm{i}}\right\} \text { and } \\
& \delta_{v}=\Sigma_{\mathrm{it}} \mathrm{H}_{\mathrm{it}}{ }^{2}=\left(1-\alpha_{v}\right)\left\{\sum_{\mathrm{it}} \mathrm{C}_{\mathrm{it}}{ }^{2}-\left(\sum_{\mathrm{it}} \mathrm{C}_{\mathrm{it}}\right)^{2} / \Sigma_{\mathrm{i}} \mathrm{T}_{\mathrm{i}}\right\} .
\end{aligned}
$$

The census parameters $\alpha_{\rho}$ and $\alpha_{v}$ in the above error sums of squares are internal-consistency reliabilities used in psychological testing (Lord and Novick,1968; Nunnally and Bernstein, 1994). Alternative formulas for internal-consistency reliability, also known as coefficient alpha (Cronbach, 1952), are given by (A.1) and (A.2) in the Appendix.

Identifications (5.2a) and (5.2b) are conditioned on measurement errors in $\left\{\mathrm{K}_{\mathrm{it}} \mathrm{F}_{\mathrm{it}} \mathrm{G}_{\mathrm{it}} \mathrm{H}_{\mathrm{it}}\right\}$

- summing to zero and

- being uncorrelated with each other and with true scores in $\left\{\eta_{\text {it }} \tau_{\text {it }} \rho_{\text {it }} v_{\text {it }}\right\}$

over $\mathrm{t}=1, \ldots, \mathrm{T}_{\mathrm{i}}$ for $\mathrm{i}=1, \ldots, \mathrm{N}$ (cf. Bound, Brown, and Mathiowetz, 2001; Bechtel, 2010).

\subsection{Estimation from the BHPS sample}

True intercepts and slopes. The rightmost identifications in (5.2a) and (5.2b) provide inferential targets for estimation from our BHPS sample. Thus, our true intercepts and slopes are estimated as

$$
\begin{aligned}
& (\hat{\kappa} \hat{\beta} \hat{\theta})^{\mathbf{T}}=\left[\sum \mathrm{w}_{\mathrm{i}} \mathrm{Z}_{\mathrm{it}} \mathrm{Z}_{\mathrm{it}}{ }^{\mathbf{T}}-\hat{\Delta}\right]^{-\mathbf{1}} \sum \mathrm{w}_{\mathrm{i}} \mathrm{Z}_{\mathrm{it}} \mathrm{U}_{\mathrm{it}} \text { and } \\
& (\hat{\lambda} \hat{\gamma} \hat{\omega})^{\mathbf{T}}=\left[\sum \mathrm{w}_{\mathrm{i}} \mathrm{Z}_{\mathrm{it}} \mathrm{Z}_{\mathrm{it}}{ }^{\mathbf{T}}-\hat{\Delta}\right]^{-\mathbf{1}} \sum \mathrm{w}_{\mathrm{i}} \mathrm{Z}_{\mathrm{it}} \mathrm{D}_{\mathrm{it}} .
\end{aligned}
$$

The weighted totals in (5.3a) and (5.3b) run over $t=1, \ldots, T_{i}$ for $i=1, \ldots, n$, where $n$ is the size of our sample of BHPS panelists. The matrix $\hat{\Delta}=\operatorname{diag}\left(0 \hat{\delta}_{\rho} \hat{\delta}_{v}\right)$, where the estimated error sums of squares are

$$
\begin{aligned}
& \hat{\delta}_{\rho}=\left(1-\hat{\alpha}_{\rho}\right)\left\{\sum_{\mathrm{it}} \mathrm{W}_{\mathrm{i}} \mathrm{A}_{\mathrm{it}}{ }^{2}-\left(\sum_{\mathrm{it}} \mathrm{W}_{\mathrm{i}} \mathrm{A}_{\mathrm{it}}\right)^{2} / \sum_{\mathrm{i} \mathrm{W}_{\mathrm{i}}} \mathrm{T}_{\mathrm{i}}\right\} \text { and } \\
& \hat{\delta}_{v}=\left(1-\hat{\alpha}_{v}\right)\left\{\sum_{\mathrm{it}} \mathrm{W}_{\mathrm{i}} \mathrm{C}_{\mathrm{it}}{ }^{2}-\left(\sum_{\mathrm{it}} \mathrm{W}_{\mathrm{i}} \mathrm{C}_{\mathrm{it}}\right)^{2} / \Sigma_{\mathrm{i} \mathrm{W}_{\mathrm{i}}} \mathrm{T}_{\mathrm{i}}\right\} \text {. }
\end{aligned}
$$


The longitudinal weights $\mathrm{w}_{\mathrm{i}}$ for sampled panelists are given by the BHPS

(http://www.esds.ac.uk/longitudinal). Each weight covers the sequence of years individual i was monitored within the span of 12 survey waves from 1997 to 2008 (cf. Section 4). The

estimated alphas $\hat{\alpha}_{\rho}$ and $\hat{\alpha}_{v}$ in (5.4a) and (5.4b) ensure that the slopes in (5.3a) and (5.3b) have been corrected for attenuation due to measurement errors in predictor scores $A_{i t}$ and $C_{i t}$. The estimator of coefficient alpha and its sampling variance are given by (A.4) and (A.5) in the Appendix.

Finally, the weighted sample sums on the right sides of (5.3a) and (5.3b) estimate the corresponding census totals in (5.2a) and (5.2b). The diagonal correction matrix $\hat{\Delta}$ in (5.3a) and (5.3b) generalizes randomization-based regression estimators, which are obtained when $\hat{\Delta}=0$ (cf. Chaudhuri and Stenger, 2005; Opsomer, 2009; Godambe and Thompson, 2009; Lohr, 2010). The true-value theory justifying this generalization is given by Bechtel (2010).

Standard errors of intercepts and slopes. To obtain the standard errors of the estimators in (5.3a) we start with

$$
\operatorname{Var}_{0}(\hat{\kappa} \hat{\beta} \hat{\theta})^{\mathrm{T}}=\mathbf{B}^{-1} \operatorname{Var}\left[\sum_{\mathrm{i}} \mathrm{Z}_{\mathrm{it}}\left(U_{i t}-\hat{U}_{i t}\right)\right] \mathbf{B}^{-1},
$$

where $\hat{U}_{i t}=\mathrm{Z}_{\mathrm{it}}^{\mathrm{T}}(\hat{\kappa} \hat{\beta} \hat{\theta})^{\mathrm{T}}$ and $\mathrm{B}=\sum \mathrm{w}_{\mathrm{i}} \mathrm{Z}_{\mathrm{it}} \mathrm{Z}_{\mathrm{it}}^{\mathrm{T}}-\hat{\Delta}$ (cf. Bechtel, 2010, Appendix). (5.5), which is an underestimate of the covariance matrix of $(\hat{\kappa} \hat{\beta} \hat{\theta})^{\mathrm{T}}$ initializes the following iterations:

$$
\begin{aligned}
\operatorname{Var}_{q}(\hat{\kappa} \hat{\beta} \hat{\theta})^{\mathrm{T}} & =\operatorname{Var}_{0}(\hat{\kappa} \hat{\beta} \hat{\theta})^{\mathrm{T}}+\mathbf{B}^{-1} \hat{\Delta} \operatorname{Var}_{q-1}(\hat{\kappa} \hat{\beta} \hat{\theta})^{\mathrm{T}} \hat{\Delta} \mathbf{B}^{-1} \\
& \cong \operatorname{Var}_{q-1}(\hat{\kappa} \hat{\beta} \hat{\theta})^{\mathrm{T}} \quad \text { for } \mathrm{q}=1,2, \ldots
\end{aligned}
$$

Upon convergence we estimate the 3 x 3 covariance matrix of (5.3a) from the final iteration in (5.6). The square roots of the three diagonals of this last matrix are the standard errors of $\hat{\kappa}$, $\hat{\beta}$, and $\hat{\theta}$ in (5.3a).

An identical procedure is carried out for obtaining the standard errors of the intercept and slopes in (5.3b). Table 6 reports the standard errors given by (5.6) for data syntax it in the column labeled "Between-and-within panelists".

\section{True-Value Regression in Data Syntaxes $i$. and it $-i$.}

\subsection{Inter-individual variation over $i$.}

Overwriting the subscript it by the subscript i. in Sections 3, 4, and 5 gives

$$
\left\{U_{\text {i. }} D_{\text {i. }} A_{\text {i. }} C_{\text {i. }}\right\},
$$




$$
\begin{aligned}
& \left\{\eta_{\text {i. }} \tau_{\text {i. }} \rho_{\text {i. }} v_{\text {i. }}\right\} \text {, and } \\
& \left\{K_{\text {i. }} F_{\text {i. }} G_{\text {i. }} H_{\text {i. }}\right\}
\end{aligned}
$$

where $i$. denotes individual i's mean over her (his) waves $\mathrm{t}=1 \ldots \mathrm{T}_{\mathrm{i}}$. Each of the four error variables in $\left\{\mathrm{K}_{\mathrm{i} .} \mathrm{F}_{\mathrm{i}}, \mathrm{G}_{\mathrm{i} .} \mathrm{H}_{\mathrm{i}}\right\}$ sums to zero under the zero-sum error assumption for syntax it in Section 5.1. However, to satisfy the correlative error assumption in syntax i. we require the additional vanishing totals

$$
\sum_{\mathrm{i}} \Sigma_{\mathrm{t}} \mathrm{P}_{\mathrm{i} .} \mathrm{Q}_{\mathrm{i} .}=0 \text { over } \mathrm{t}=1, \ldots, \mathrm{T}_{\mathrm{i}} \text { for } \mathrm{i}=1, \ldots, \mathrm{N} .
$$

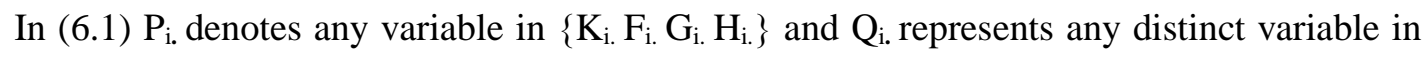
$\left\{\mathrm{K}_{\mathrm{i} .} \mathrm{F}_{\mathrm{i} .} \mathrm{G}_{\mathrm{i} .} \mathrm{H}_{\mathrm{i} .}\right\}$ or $\left\{\eta_{\mathrm{i} .} \tau_{\mathrm{i} .} \rho_{\mathrm{i}}, v_{\mathrm{i}}\right\}$.

Under (6.1), it is easy to show that mean errors are uncorrelated with each other and with mean true scores. Then (5.2.a) and (5.2b), with subscript it overwritten by $i$, identify the true slopes of $\eta_{\mathrm{i} .}$ on $\rho_{\mathrm{i}}$ and $v_{\mathrm{i} \text {. }}$ and $\tau_{\mathrm{i} .}$ on $\rho_{\mathrm{i} \text {. and }} v_{\mathrm{i} .}$. Equations (5.3a) and (5.3b), again with $i$. overwriting $i t$, estimate these true slopes by adjusting for measurement errors in mean scores $A_{i}$ and $C_{i .}$. Slope standard errors, estimated from (5.6) in syntax $i$, are reported in the "Between panelists" column of Table 6 .

\subsection{Intra-individual variation over $i t-i$.}

Finally, we designate intra-panelist deviation scores by overwriting the subscript it with it$i$. in Sections 3, 4, and 5. This gives

$$
\begin{aligned}
& \left\{U_{i t-i .} D_{i t-i .} A_{i t-i .} C_{i t-i .}\right\}, \\
& \left\{\eta_{i t-i .} \tau_{i t-i .} \rho_{i t-i .} v_{i t-i .}\right\}, \quad \text { and } \\
& \left\{K_{i t-i .} F_{i t-i .} G_{i t-i .} H_{i t-i .}\right\},
\end{aligned}
$$

where $\mathrm{t}=1 \ldots \mathrm{T}_{\mathrm{i}}$ for $\mathrm{i}=1 \ldots \mathrm{N}$. For example, $\mathrm{U}_{\mathrm{it}-\mathrm{i} .} \equiv \mathrm{U}_{\mathrm{it}}-\mathrm{U}_{\mathrm{i}}$, and it follows that $\mathrm{U}_{\mathrm{it}-\mathrm{i} .}=\eta_{\mathrm{it}-\mathrm{i} .}+\mathrm{K}_{\mathrm{it}-\mathrm{i}}$ (cf. equation 3.1).

Measurement-error deviations in $\left\{\mathrm{K}_{\mathrm{it-i} \text {. }} \mathrm{F}_{\mathrm{it}-\mathrm{i} . \mathrm{G}} \mathrm{G}_{\mathrm{it-i}} \mathrm{H}_{\mathrm{it}-\mathrm{i}}\right\}$ sum to zero over $\mathrm{t}=1 \ldots \mathrm{T}_{\mathrm{i}}$ for $\mathrm{i}=1 \ldots \mathrm{N}$. Under (6.1) these error deviations are also uncorrelated with each other and with the true deviation scores in $\left\{\eta_{\text {it-i. }} \tau_{\text {it-i. }} \rho_{\text {it-i. }} v_{\text {it-i. }}\right\}$. Then (5.2a) and (5.2b), with it overwritten by it $-i$., identify the true slopes of $\eta_{\text {it-i. }}$ on $\rho_{\text {it-i. }}$ and $v_{\text {it-i. }}$ and $\tau_{\text {it-i. }}$ on $\rho_{\mathrm{it}-\mathrm{i}}$ and $v_{\mathrm{it}-\mathrm{i}}$. These slopes, which are corrected for errors in $\mathrm{A}_{\mathrm{it-i.}}$ and $\mathrm{C}_{\mathrm{it}-\mathrm{i} \text {, }}$, are estimated by overwriting $i t$ by $i t-i$. in equations (5.3a) and (5.3b).

Slope standard errors in syntax it $-i$. could not be estimated from (5.6) due to convergence failure. Therefore, we report underestimated standard errors from (5.5) in the "Within panelists"

column in Table 6. Our resort to (5.5) assumes that the correction matrix $\hat{\Delta}$ in (5.3a) and (5.3b) is fixed rather than random.

\section{Ill-Being in the United Kingdom}




\subsection{Correlations between unhappiness and life dissatisfaction}

The distinction between unhappiness and life dissatisfaction is demonstrated in Table 4 by the low correlations between scores $U_{i t}$ and $D_{i t}$, individual means $U_{i .}$ and $D_{i .}$, and withinindividual deviations $\mathrm{U}_{\text {it-i. }}$ and $\mathrm{D}_{\text {it-i. }}$. The between-panelist correlation exceeds the overall correlation which, in turn, surpasses the within-panelist correlation. This rank order is expected because inter-individual differences are greater than intra-individual differences.

These low correlations in all three data syntaxes reject the conflation between unhappiness and dissatisfaction perpetuated by the social indicators movement (cf. Section 1).

Table 4: Relationships between Unhappiness and Life Dissatisfaction

\begin{tabular}{lccc} 
Data syntax & $\begin{array}{c}\text { Between } \\
\text { panelists }\end{array}$ & $\begin{array}{c}\text { Between-and- } \\
\text { within panelists }\end{array}$ & $\begin{array}{c}\text { Within } \\
\text { panelists }\end{array}$ \\
\hline Correlation & $.55(.0000)$ & $.41(.0000)$ & $.34(.0000)$ \\
\hline Sample size & 69351 & 62164 & 62164 \\
\hline
\end{tabular}

Note: The significance level for each correlation is in parentheses.

\subsection{Reliabilities of Depression Scores}

Table 5 exhibits reliabilities of our two depression scores computed from formulas in the Appendix. Each of these alpha coefficients is a Horvitz-Thompson-type estimate of internalconsistency reliability. The first row of Table 5 gives $\hat{\alpha}_{\rho}$ in (5.4a) for the $i$. , it, and $i t-i$. data syntaxes. The second row displays $\hat{\alpha}_{v}$ in $(5.4 \mathrm{~b})$ for the same syntaxes. These alpha coefficients are based on the depression items in Table 2.

Two main effects stand out in Table 5. First, affective depression is more reliably measured than cognitive depression. Second, between-panelist means are more reliable than overall panel scores which, in turn, are more reliable than within-panelist deviations. This order of reliabilities is expected from the fact that inter-individual variation exceeds intra-individual variation. The standard errors of these alpha coefficients show that the two main effects in Table 5 are highly significant. 
Table 5: Alpha Coefficients for Three Data Syntaxes

\begin{tabular}{lccc} 
Data syntax & $\begin{array}{c}\text { Between } \\
\text { panelists }\end{array}$ & $\begin{array}{c}\text { Between-and- } \\
\text { within panelists }\end{array}$ & $\begin{array}{c}\text { Within } \\
\text { panelists }\end{array}$ \\
\hline Affective depression & $.93(.0005)$ & $.88(.0010)$ & $.80(.0018)$ \\
Cognitive depression & $.89(.0012)$ & $.81(.0020)$ & $.76(.0027)$ \\
\hline
\end{tabular}

Note: The computations of the alpha coefficients and their standard errors (in parentheses) are described in the Appendix.

\subsection{Effects of depression on ill-being}

The reliability coefficients in Table 5 correct the regression slopes in Table 6 for attenuation due to measurement errors in our depression scores. The slopes in Table 6 reveal a striking reversal for affective and cognitive depression underlying unhappiness and life dissatisfaction. Cognitive depression is the primary driver of unhappiness, whereas affective depression is the main cause of life dissatisfaction. This distinction is consistent with the low correlations between unhappiness and dissatisfaction in Table 4.

Unhappiness. The slopes in the first two rows of Table 6 were computed from Formula (5.3a) in the $i$., it, and $i t-i$. data syntaxes. These slopes show that cognitive depression dominates affective depression in driving unhappiness in all three syntaxes.

Life dissatisfaction. Conversely, the slopes in the last two rows of Table 6 demonstrate the dominance of affective depression in generating life dissatisfaction in each data syntax. These slopes were computed from Formula (5.3b).

Cross validation. The full-sample results in Tables 1 and 6 were cross-validated on a holdout sample (http://en.wikipedia.org/wiki/Cross-validation_(statistics)). First, the BHPS sample was randomly split into a training dataset of 34580 cases and a testing dataset of 34846 cases. Next, the factor analysis in Section 2, and the regressions in Sections 5 and 6, were run on the training sample. These analyses again produced the affective and cognitive depression factors in Table 1 and the syntactic regression pattern in Table 6. Finally, the training-sample regression coefficients were applied to the holdout sample's depression scores. This generated a holdout mean squared error (MSE) for each of the six syntactic regressions. The ratios of the holdout MSEs to the training-sample MSEs ranged from .992 to 1.004, showing very slight loss in predictive power for true-value regression coefficients. 
Table 6: True-Value Regression Slopes for Panel Data Syntaxes

$\begin{array}{llll}\text { Data syntax } & \begin{array}{c}\text { Between } \\ \text { panelists }\end{array} & \begin{array}{c}\text { Between-and- } \\ \text { within panelists }\end{array} & \text { Within } \\ \text { panelists }\end{array}$

\section{Unhappiness on:}

$\begin{array}{lcccc}\text { Affective depression } & .15(.004) & .22(.010) & .39(.014) \\ \text { Cognitive depression } & .82(.008) & .85(.017) & .76(.019) \\ \text { Life dissatisfaction on: } & & & \\ \text { Affective depression } & .68(.006) & .62(.016) & .43(.015) \\ \text { Cognitive depression } & .19(.011) & .11(.026) & .19(.021)\end{array}$

Notes: Each of these six analyses is a weighted true-value regression in a panel data syntax. The standard errors (in parentheses) for syntaxes $i$. and it were iteratively obtained from (5.6). Iterative variance estimation failed to converge in syntax $i t-i$., and starting values in (5.5) were used as variance estimates.

This assumes that the correction matrix $\hat{\Delta}=\operatorname{diag}\left(0 \hat{\delta}_{\rho} \hat{\delta}_{v}\right)$ in (5.3a) and (5.3b), when overwritten for deviation data, is fixed rather than random (cf. Section 5.2 and Bechtel, 2010, Appendix). Thus, the standard errors in the last column are understated for the two within-panelists regressions.

The hypothesis of slope equality was rejected at the .0000 level of significance in each $i$. and it regression. This hypothesis was also rejected at the .0000 level in each $i t-i$. regression using doubled standard errors. The number of observations in each unhappiness regression is 68498 . The number of observations in each dissatisfaction regression is 62204 because the BHPS did not include the life satisfaction item in 2001

\section{True-Value Regression in Micro Data Syntaxes}

True-value regression accurately estimates relationships between population variables at different levels of important micro data:

Panel data. In the present paper micro variations in ill-being are predicted by two depression indicators constructed from the British Household Panel Survey. Panel regression effects are corrected for errors in these predictors, which attenuate slopes estimated by traditional panel regressions. These corrections, carried out on a large high-quality dataset, reveal that unhappiness and life dissatisfaction are distinct variables with very different psychological causations.

True effects of affective and cognitive depression are measured in three data syntaxes: between individuals, within individuals, and between and within individuals overall. Table 6 exhibits a striking role reversal between cognitive and affective depression in each syntax. Cognitive depression drives unhappiness, whereas affective depression drives life dissatisfaction. 
These distinctive psychological processes explain the low correlations between unhappiness and life dissatisfaction reported in Table 4, also in each data syntax. Clearly, future efforts to measure ill-being should untangle the conflation of unhappiness and life dissatisfaction that has pervaded social-indicators research since the 1970's.

Cross-national data. In addition to panel data from a single nation, cross-national datasets may be syntactically regressed. Letting c denote a country and i an individual, our three syntaxes become: between countries, within countries, and between and within countries overall. Future cross-national research, with high-quality datasets such as the European Social Survey (Fitzgerald, 2013), would benefit from true-value regressions run in each of these three data syntaxes. The added values delivered by such analyses are a) more accurate estimation of regression slopes, b) multi-level assessment of these slopes, and c) confirmation of micro relationships over data syntaxes. These advantages exist for each survey and, in the case of repeated surveys like the European Social Survey, syntactic changes in micro relationships can be monitored over time.

\section{Appendix: Coefficient Alpha}

In Section 2 and Table 2 let $S_{\text {itm }}$ be a $[0,10]$ item score and $S_{\text {it }}$ be a $[0,10]$ construct score. Thus, an M-item construct score $S_{i t}$ is the average $M^{-1} \sum_{m} S_{i t m}$ of its item scores, where $M=6$ for affective depression, and $\mathrm{M}=5$ for cognitive depression.

This Appendix gives a construct's census alpha, its sample estimate, and the sampling variance of this estimate. The estimated alphas for affective and cognitive depression, along with their standard errors, appear in the between-and-within column of Table 5 for syntax $i t$.

\section{A.1 Census Definition of Alpha in Data Syntax it}

Coefficient alpha is the standard measure of internal-consistency reliability of a psychological test. Bechtel (2013) shows that this coefficient is the ratio of a construct's truescore variance to its observed-score variance. However, in defining alpha it is not necessary to have a construct's true scores. The power of this coefficient lies its definition of reliability solely in terms of observable item scores $S_{\text {itm }}$ and their average (construct) score $S_{\text {it }}$.

We write the census coefficient alpha as

$$
\alpha=\frac{M}{M-1}\left[1-\frac{\sum_{i} \sum_{t} \sum_{m}\left(S_{i t m}-S_{. m}\right)^{2}}{M^{2} \sum_{i} \sum_{t}\left(S_{i t}-S_{. .}\right)^{2}}\right],
$$

where summations run over $\mathrm{t}=1 \ldots \mathrm{T}_{\mathrm{i}}$ for $\mathrm{i}=1 \ldots \mathrm{N}$ and $\mathrm{m}=1 \ldots \mathrm{M}$. Defining

$\mathrm{R}_{\mathrm{it}} \equiv \Sigma_{\mathrm{m}}\left(\mathrm{S}_{\mathrm{itm}}-\mathrm{S}_{. . \mathrm{m}}\right)^{2}$, we have $\Sigma_{\mathrm{i}} \Sigma_{\mathrm{t}} \Sigma_{\mathrm{m}}\left(\mathrm{S}_{\mathrm{itm}}-\mathrm{S}_{. . \mathrm{m}}\right)^{2}=\Sigma_{\mathrm{i}} \Sigma_{\mathrm{t}} \mathrm{R}_{\mathrm{it}} \equiv \mathrm{R}$. Also, defining $\mathrm{V}_{\mathrm{it}} \equiv\left(\mathrm{S}_{\mathrm{it}}-\right.$ $\left.\mathrm{S}_{\text {.. }}\right)^{2}$, we have $\Sigma_{\mathrm{i}} \Sigma_{\mathrm{t}}\left(\mathrm{S}_{\mathrm{it}}-\mathrm{S} . .\right)^{2}=\Sigma_{\mathrm{i}} \Sigma_{\mathrm{t}} \mathrm{V}_{\mathrm{it}} \equiv \mathrm{V}$. Then, given the fixed number $\mathrm{M}$ of items in score $\mathrm{S}_{\mathrm{it}}$, our census alpha may be rewritten as the following linear function of the ratio $\mathrm{R} / \mathrm{V}$ :

$$
\alpha=M(M-1)^{-1}-M^{-1}(M-1)^{-1}(R / V) .
$$




\section{A.2 Sample Estimation in Data Syntax it}

Sampling our census gives an estimate of alpha by replacing the ratio R/V in (A.2) by its well-known estimator

$$
\hat{R} / \hat{V}=\frac{\sum_{i} \sum_{t} w_{i} R_{i t}}{\sum_{i} \sum_{t} w_{i} V_{i t}}
$$

(cf. Thompson, 1997, p. 96). The two summations in (A.3) run over $t=1 \ldots T_{i}$ for $i=1 \ldots$ n. The longitudinal weights $\mathrm{w}_{\mathrm{i}}$ are described in Section 4. StataCorp (2011) provides the computation of $\hat{R} / \hat{V}$, along with the linearized estimate $\operatorname{Var}(\hat{R} / \hat{V})$ of its sampling variance. These two estimates give

$$
\begin{aligned}
& \hat{\alpha}=M(M-1)^{-1}-M^{-1}(M-1)^{-1}(\hat{R} / \hat{V}) \text { and } \\
& \operatorname{Var}(\hat{\alpha})=\left[M^{-1}(M-1)^{-1}\right]^{2} \operatorname{Var}(\hat{R} / \hat{V}) .
\end{aligned}
$$

The square root of $\operatorname{Var}(\hat{\alpha})$ is the standard error for each alpha coefficient in the betweenand-within column of Table 5.

\section{A.3 The Reliability of $i$. and $i t-i$. Panel Scores}

The alpha coefficients and standard errors in the between column of Table 5 are obtained by overwriting the subscript it by $i$. in this Appendix. The estimates in the within column of Table 5 are given by overwriting it by $i t-i$. . Note that a construct or item score has the same overall mean in the $i t$ and $i$. data syntaxes. In syntax $i t-i$. this overall mean is zero.

\section{Acknowledgements}

The author thanks Kenneth Brantley and Forrest Morlan at the University of Florida Computing Help Desk. The JDS reviewer's suggestions about standard errors have improved this work. Our BHPS data were supplied under a contract with ESDS Longitudinal in the UK Data Archive at the University of Essex. The opinions and analyses in the present paper are the author's alone and are not attributable to the University of Florida, ESDS Longitudinal, or the Journal of Data Science.

\section{References}

[1] Andrews, F. M. and Withey, S. B. (1974). Developing measures of perceived life quality: Results from several national surveys. Social Indicators Research 1, 1-26. 
[2] Andrews, F. M. and Withey, S. B. (1976). Social Indicators of Well-Being: American's Perceptions of Life Quality. New York: Plenum Press.

[3] Atkinson, T. (1982). The stability and validity of quality of life measures. Social Indicators Research 10, 113-132.

[4] Bechtel, G.G. (2010). True-value regression theory. Journal of Data Science 8, 521-539.

[5] Bechtel, G. G. (2013). Public opinion about income inequality. Electronic Journal of Applied Statistical Analysis 6, 238-259.

[6] Bechtel, G. G. (2014). Does sentiment or anxiety drive consumer demand? Journal of Data Science 12, 19-34.

[7] Bechtel, T. G. (2007). The pursuit of happiness. Survey Research Methods 1, 109-120.

[8] Bound, J., Brown, C. and Mathiowetz, N. (2001). Measurement error in survey data. In Handbook of Econometrics, Volume 5 (Edited by J. J. Heckman and E. Leamer), 37053843. Amsterdam: Elsevier Science.

[9] Bradburn, N. M. (1969). The Structure of Psychological Well-Being. Hawthorne: Aldine. Chaudhuri, A. and Stenger, H. (2005). Survey Sampling: Theory and Methods, second edition. Boca Raton FL: CRC Press.

[10]Cronbach, L. J. (1951). Coefficient alpha and the internal structure of tests. Psychometrika 16, 297-334.

[11]Fitzgerald, R. (2013). European Social Survey, European Research Infrastructure Consortium, Centre for Comparative Social Surveys, City University London, U.K. (http://www.europeansocialsurvey.org)

[12] Godambe, V. P. and Thompson, M. E. (2009). Estimating functions and survey sampling. In Handbook of Statistics, Volume 29B (Sample Surveys: Inference and Analysis) (Edited by D. Pfeffermann and C. R. Rao), 83-101. Amsterdam: Elsevier.

[13] Gundelach, P. and Kreiner, S. (2004). Happiness and life satisfaction in advanced European countries. Cross-Cultural Research 38, 359-386.

[14]Guttman, L. and Levy, S. (1982). On the definition and varieties of attitude and wellbeing. Social Indicators Research 10, 159-174.

[15]Huppert, F. A. and So, T. T. C. (2013). Flourishing across Europe: Application of a new conceptual framework for defining well-being. Social Indicators Research 110, 837-861. 
[16]Inglehart, R. and Klingemann, H. (2000). Genes, culture, democracy, and happiness. In Culture and Subjective Well-Being. (Edited by E. Diener and E. M. Suh), 165-183. Cambridge MA: MIT Press.

[17]Jackson, C. (2007). The General Health Questionnaire. Occupational Medicine 57, 79.

[18]Keyes, C. L. M. (2007). Promoting and protecting mental health as flourishing: A complementary strategy for improving national mental health. American Psychologist 62, 95-108.

[19]Lohr, S. L. (2010). Sampling: Design and Analysis, $2^{\text {nd }}$ edition. Boston: Brooks/Cole.

[20]Lord, F. M. and Novick, M. R. (1968). Statistical Theories of Mental Test Scores. Menlo Park CA: Addison-Wesley.

[21]Michalos, A. C. (2004). Social indicators research and health related quality of life research. Social Indicators Research 65, 27-72.

[22]Nunnally, J. C. and Bernstein, I. H. (1994). Psychometric Theory, $3^{\text {rd }}$ edition. New York: McGraw-Hill.

[23]Opsomer, J. D. (2009). Introduction to Part 4: Alternative approaches to inference from survey data. In Handbook of Statistics, Volume 29B (Sample Surveys: Inference and Analysis) (Edited by D. Pfeffermann and C. R. Rao), 3-9. Amsterdam: Elsevier.

[24]Pevalin, D. J. (2000). Multiple applications of the GHQ-12 in a general population sample: an investigation of long-term retest effects. Social Psychiatry and Psychiatric Epidemiology 35, 508-512.

[25]StataCorp. (2011). Stata Statistical Software: Release 12. College Station, TX: StataCorp LP.

[26]Tatarkiewicz, W. (1976). Analysis of Happiness. Warsaw: PWN - Polish Scientific Publishers.

[27]Thompson, M. E. (1997). Theory of Sample Surveys. London: Chapman \& Hall.

[28]Van Praag, B. M. S. and Ferrer-i-Carbonell, A. (2004). Happiness Quantified: A Satisfaction Calculus Approach. Oxford: Oxford University Press.

[29]Veenhoven, R. (1991). Questions on happiness: classical topics, modern answers, blind spots. In Subjective Well-Being: An Interdisciplinary Perspective. (Edited by F. Argyle, N. Schwarz, and N. Strack), 7-26. Elmsford NY: Pergamon Press. 
Gordon G. Bechtel

Received August 13, 2013; accepted April 12, 2014.

University of Florida and Florida Research Institute

Gainesville, Florida 32611-7155, P.O. Box 117155, USA

bechtel@ufl.edu 